\title{
Truth and Method in Southern Criminology
}

\author{
Mark Brown ${ }^{1,2}$
}

Accepted: 4 August 2021 / Published online: 1 September 2021

(c) Crown 2021

\begin{abstract}
What does it mean to "do" southern criminology? What does this entail and what demands should it place on us as criminologists ethically and methodologically? This article addresses such questions through a form dialogue between the Global North and the Global South. At the center of this dialogue is a set of questions about ethical conduct in the pursuit of knowledge and understanding in human relations. These develop into a conversation that engages South Asian scholars working at the forefront of critical social science, history and theory with a foundational text of European hermeneuticist theory and practice, Hans-Georg Gadamer's Truth and Method, published in 1960. Out of this exercise in communication across culture, histories and knowledge practices emerges a new kind of dialogue and a new way of thinking about ethical practice in criminology. To give such abstractions a concrete reference point, the article illustrates their possibilities and tensions through a case study of penal reform and the question of whether so-called "failed" Northern penal methods-like the prison-should be exported to the Global South. The article thus works dialogically back and forth through these scholars' accounts of ethical conduct, research practice, the weight of history, and the work of theory with a very concrete and common criminological context in sight. The result is what might be understood as a norm of ethical engagement and an epistemology of dialogue.
\end{abstract}

\section{Introduction}

This article raises questions about how Northern or Global North-oriented criminologists might think about the Global South and, in their work, try to join in finding just futures there. In terms of what this might involve, I define "work" broadly to include advocacy, discussions, engagements, meetings, professional relationships, research and visits. In this context, I use the phrase "just futures" to refer to the goal of finding fair and satisfactory solutions to problems of order-again, broadly defined, from illegalities to social wrongs and even to ruptures of cosmological order-as they appear in those parts of the world that have been mostly invisible to mainstream criminology. I also use the term, "just futures," as a foil for thinking through some of the personal challenges faced by criminologists raised

Mark Brown

mark.brown@sheffield.ac.uk

1 University of Sheffield, Sheffield, UK

2 University of Melbourne, Melbourne, VIC, Australia 
or trained within Northern epistemic and ontological traditions as they attempt to work justly and ethically in Southern places, in Southern worlds, and in engagement with Southerners and their lives. As such, this article joins a growing number of efforts to connect criminology to broader conceptions of ethical conduct and to reflect, through an ethical lens, on Global North-Global South and postcolonial praxis (Blaustein 2016, 2017; Cunneen 2018; George et al. 2020; Walters 2016). It dovetails with approaches such as Jarrett Blaustein's (2017: 374) “ethical self-checklist that is designed to help researchers achieve a reflexive praxis" when "abroad" in the Global South. But it also goes much further than this aid-memoire approach by developing, for what I think is the first time (cf. Reiman 1979), an ethical account of the how and why of our conduct as criminologists and by suggesting the generative, discipline-expanding opportunities that Global North-Global South praxis offers. In doing so, the article moves beyond prevailing visions of ethics in Southern and postcolonial criminology by distinguishing political claims that are often framed as ethical injunctions - such as that we should not (re)impose colonial logics upon peoples and communities of the Global South (it would be unethical to do so) - from an individuallevel and formal ethical account of conduct that is grounded in Kantian morality's demand for all people(s) to be treated as fully human. As such, while grounded in the concerns of southern criminology, the implications and relevance of this approach extend to the whole discipline of criminology and, indeed, more widely to any circumstances where social scientists work in milieux marked by difference, hierarchy, imbalances of power and the like.

So, what might constitute "ethical" conduct in such circumstances? While cautioning that greater finesse and elaboration will emerge as this article progresses, I proceed, at this point, with an elementary definition that emerges from the second formulation of Immanuel Kant's categorical imperative: we must never treat another (that is, another person, another group of people) simply as a means, for that person/those people must always, as human(s), be an end in himself/herself/themselves. As I illustrate below, this seemingly uncontentious proposition in fact presents significant challenges to social science methodologies and to typical modes of Global North-Global South or postcolonial engagement. How, or why, might this be so? To illustrate, I use a case study developed from work I have undertaken with South Asian colleagues. I discuss it only in general terms with respect to its specific location, but the question of location is not critical because the problem itselfpenal reform-is common across the Global South. The questions it presents to us are, in many ways, not new-until, that is, they are posed in connection with the question of justice, itself, and of what it means to work ethically as a criminologist. What I argue is that debates about whether it is good or bad to export so-called "failed" penal technologies like the prison take a different tone when the target of these Global Northern exports is a state in the Global South (cf. Graham and Robertson 2021; Jones and Newburn 2007). Implicit in the debate is the matter of our judgment and thus how we assess the quality of these penal approaches. Here, I propose that just practice requires us to attend to the ethical implications of our own judgment. In addition, I suggest we do so through a form of reflexivity that recognizes the double-sided character of well-meaning judgment and that raises awareness of the delicate line dividing well-meaning judgment from practices of domination.

The remainder of the article proceeds as follows. First, I examine penal reform in the Global South. There is a small but long-standing criminological literature on this topic-a point at which critical, progressive criminology meets the globalization of penal reform initiatives, often tied to narratives and strategies of "modernization" and "development." Second, and moving into the sphere of ethics, I engage with the work of the German hermeneutical philosopher Hans-Georg Gadamer, primarily through his text Truth and 
Method (1960). Gadamer's work has been influential in many spheres, including in the Global South. The productive engagement with his ideas that has occurred there constitutes the third and fourth part of this article, but I will begin here with an outline of Gadamer's key arguments and, in particular, his account of how forms of progressive welfare work - which takes in much of what criminology does - may slide easily into practices of domination. In parts three and four, two visions from South Asia of how ethics and history shape knowledge under conditions of hierarchical domination are introduced. In the first, Guru and Sarukkai (2012) debate questions of experience and theory with specific reference to India's Dalits - an oppressed segment of India's population known also to some caste Hindus as "untouchables." After a discussion of Guru and Sarukkai's understanding of domination, ethics and hierarchies, I engage with the work of Prathama Banerjee, Aditya Nigam and Rakesh Pandey (2016), who broaden and develop these ideas to consider "the work of theory" and the conditions under which forms of knowledge freed from hierarchical domination might emerge. Finally, I draw all of this together by returning to Gadamer, blending ideas flowing from these South Asian dialogues with his own notion of "dialogue as method." I conclude by suggesting how criminologists might find within these quite disparate traditions of thinking what I term a "norm of ethical engagement" and an "epistemology of dialogue" suitable for a southern criminology.

\section{Penal Reform in the Global South}

About 85\% of the world's population lives in the Global South (UN 2018) and much of what we refer to today as the "Global South" has a long history of former colonial occupation. One cannot identify a precise date on which formal European imperialism ended and new and notionally independent nation-states emerged: decolonization of parts of Latin America began in the early nineteenth century and continued through the twentieth century in South Asia. In the 1960s, Africa experienced a tidal wave of decolonization and, in 1960 alone, for example, seventeen new nation-states came into existence on the continent. Yet, the retreating colonial powers and their forms of rule that spread globally since the discovery of the "New World" in the late-fifteenth century left myriad residues. Among the least loved of them all was and continues to be the prison (Dikotter and Brown 2007), which retains a certain, often decrepit, presence in the institutional architecture of states of the Global South. This crumbling presence is often shackled to an equally creaky judicial system also of colonial origin. To take three South Asian states as examples, the inertia of courts in Bangladesh, India, and Pakistan can partly explain the fact that in 2015, individuals on trial comprised $74 \%, 67 \%$ and $69 \%$ of these countries' prison populations, respectively (UNODC 2020). Not only are these rates high, but prisoners often languish in "undertrial" custody for years. Surely, then, these must be sites ripe for reform and for the transfer of some better knowledge of "how to do things." And, indeed, they have been subject to a substantial amount of such advice.

These circumstances beg the following questions: how should Northern or Global Northoriented criminologists respond? What role should they play in the export, transfer or translation of Northern penal approaches, based on their supposedly greater experience and more efficient and developed models, to countries that lack them or where they are "weak" or "underdeveloped" or simply crumbling? Of course, these are not new questions, nor do their answers rest solely with those who study penal systems (Bowling 2011; Walklate and Fitz-Gibbon 2018). Nor is it a purely an issue of technical knowledge because there are clear 
threads linking criminology's self-conception with the way it approaches the transfer and communication of its knowledge beyond its metropolitan academies (Carrabine et al. 2020). Indeed, the discipline has a history of responding to these questions since at least the time of Clinard and Abbott's Crime in Developing Countries: A Comparative Perspective (1973)—a study and proposed modernization thesis for Uganda made just a few years after its independence. Critical responses to such advice-giving began to emerge not long after that. Early examples appear in a collection edited by Colin Sumner, Crime, Justice and Underdevelopment (1982), which subjected the modernization approach to various forms of fairly negative appraisal. Probably the clearest critique of Global North-Global South "transfer" was made by Stanley Cohen in an essay, "Western crime control models in the Third World: Benign or malignant?" (in Cohen 1988). Thirty years and thousands of well-meaning penal reform programs later, that critical perspective continues to be advanced by criminologists. In the process, new terms have been coined to capture all the reforming and transforming activity, such as "penal aid" (Brisson-Bovin and O'Connor 2013), "penal humanitarianism" (Bosworth 2017; Lohne 2020) and "penal neo-colonialism" (Stambøl 2021). One recent example of this literature is an article by Deborah Drake, "Prisons and state building: Promoting "the fiasco of the prison" in a global context" (2018). In the parts below, I draw on Drake's distillation of some of criminology's progressive arguments as they are made in the context of penal reform in the Global South, but I use her work mainly for convenience as a particularly clear, spirited and contemporary articulation of a long-standing critical tradition of work within the discipline.

Drawing on this tradition of work, Drake (2018: 11) summarizes that:

Prisons operate as repressive, unconstitutional spaces. They begin from the premise that the citizens they govern will not be afforded the same rights and freedoms as other social members. They stigmatise those they imprison, setting "them" apart from "us". This function is reinforced by and, in turn, reinforces the principles of othering that are implicit in declared states of emergency and which accompany ideologies of security.

For Drake (2018: 2), the persistent efforts to "create 'better' prison places and systems" are a sham and will only be brought to an end when everyone engages "more honestly" and tells "the 'truth about prisons'." What, indeed, is there to argue with her observation of a profound "disconnection between the assumed or imagined function of prisons ... and their abject failure to consistently operate humanely or to fulfil their stated goals" (Drake 2018: 2)? Recognizing the huge body of research that stands behind such conclusions and looking across a critical literature spanning almost forty years, what more is there to be said? Penal reform is a useful example for us here for this very reason.

To challenge the case against penal reform in the Global South is, I well recognize, not to be taken lightly for it also challenges one of the shibboleths of critical and progressive criminology. By extension, it also challenges the nature of progressive projects like southern criminology itself. My aim in doing so, in fact, has very little to do with the quality of what is said about prisons or other penal measures-whether they are good or badand is, instead, an intervention into the field of ethics, ethical conduct, and ethical practice that shines a light on the post-enlightenment tradition of progressive social movements and welfare work - something reflected in many varieties of criminology, including these critiques of penal reform. 


\section{The Ethics of Judgment: On Welfare Work and Domination}

I am not aware of any studies that analyze how criminologists of different stripes regard and engage with the moral-ethical domain of their professional lives in different spheres of crime and justice-related work (though important intimations can be found in Cain (2000)). But if the teaching of criminology - its courses, textbooks and the like-may be understood as, at least, drawing an outline of an emerging professional habitus, then we can presume that most of us engage with ethics in largely procedural terms. The moral imperative to do no harm, as taught to students, is instantiated for criminologists in a blizzard of ethics application forms and informing/disclosing statements. Within them will be found demands to identify "at risk" participant groups-for example, the young, the mentally infirm, those in hierarchical relationships to the researcher or recruiter (prisoners being a good example) - as well as risks to researchers. All the while, there is the need to keep a keen eye on litigation or reputational risks for the employing university. Jerry Johnstone (2005: 62) notes of the British Social Research Association's Ethical Guidelines that it even:

makes it quite clear that such codes emerged, less from a concern to provide serious ethical guidance to researchers genuinely troubled by some ethical dilemma, but rather from the need to meet new public and political demands upon large organizations that affect public well-being (such as universities, the police, providers of financial services, and providers of heath and social care, etc.)

The result of this bureaucratization of the most human of concerns - ethical conduct-is, as Jeff Ferrell (2011: 67) has observed, "a disciplinary moral order beset by contradiction and inconsistency, both in conceptualization and in practice, and all of this only half-hidden behind professional protestations otherwise."

When I speak of ethics, here, my concerns are far broader than the rulemaking, codifying and control of researcher conduct that is the subject of Johnson's writing. The implications of what I discuss below are, at this point, at least, principally at the level of personal criminological practice. Discussing such practice, David Rodríguez Goyes (2019: 63) has observed that from a southern green criminological perspective, "deep respect for ethical considerations has more to do with being conscious of structural conditions than with the fulfilment of protocols," such as those just discussed. I agree, but my approach here differs in that it describes the ethical impacts of structural/hierarchical domination and, in so doing, attempts to articulate precisely how and why the deep respect for ethical considerations, and thus the demands it carries with it, should arise at all. My aim, therefore, is to address the question of whether elements of Northern penality that are judged within critical criminological circles to have "failed" or are otherwise problematic should be exported to the Global South, with an eye to the ethical implications of what that act of judging entails.

In doing so, I will begin with Gadamer's Truth and Method (1960). How might Gadamer help us and how relevant is a mid-twentieth-century German hermeneuticist to criminologists looking south? It is worth noting that I did not come across Gadamer through a study of the European canon, but through the work of Indian writers to whom we will turn once the key contours of Gadamer's thought have been established. Gadamer's value, I suggest, is in breaking down Kant's categorical imperative in a manner appropriate for those of us wishing to engage across boundaries of place and history, and thus seeking a form of ethical practice in pursuit of knowledge founded on understanding. Recall that in 
its second formulation, Kant's injunction states that we must never treat another personor other groups - or another people-simply as a means. For by dint of their humanity, they must always be an end in themselves. Gadamer makes sense of this by distinguishing three possible forms of relation between ourselves and another-each progressively stronger in ethical form and, so, more capable of satisfying Kant's demand to treat others as fully human.

To begin, Gadamer proposes that the fundamental point of our connection with others may be understood as an I-Thou relationship. "A Thou is not an object," he notes, because it "relates itself to us" and, in so doing, draws us into an ethical space (Gadamer 1960/2013: 366). With one eye on social science methodologies, Gadamer observes that a first, and common, form of I-Thou relations is that where we try to determine typical behaviours of those around us and use that experience to make predictions about how specific groups or individuals will behave. ${ }^{1}$ Think of risk prediction in criminology as an obvious example. For Gadamer, "this orientation towards the Thou is purely self-regarding and contradicts the moral definition of man"" given to us by Kant (Gadamer 1960/2013: 367). In other words, in generating offender risk profiles, for example, we use others purely for our own purposes-predicting the threat they pose to us. This is the self-regarding stance, in Gadamer's language. We might delve deeper into the ethical terrain of prediction but that is not my focus here and its manifold problems are already well known in criminology (Harcourt 2007).

A second form of I-Thou relation is more typical of Global North-Global South interactions, but it is here that things also become trickier for us. For in this second case, while we recognize the other-the Thou — as a person (or people), we continue to maintain the self-orientation that was offensive to ethical conduct in the prediction example. The paradigmatic case arises in a dialogue between I and Thou that we might imagine for present purposes to concern such matters as, perhaps, the merits or desirability of some penal form or technique. Typical of such dialogues is the various perspectives of the discussants. For example, one side argues that the prison is a fiasco and brings with it only problems, while the other side responds that existing prison capacity is limited, the infrastructure is crumbling, and that there is a need to redevelop and reform this penal space. The details of the points are not important. What is important is that the dialectic of the I-Thou relationship in this form enables us to reflect on the other's claims. And that act of reflection, in turn, frequently inclines us to situate ourselves in the other's position. From there, it may be a short step to feeling that we understand their position or, as we might say colloquially that we know "where [they're] coming from" (1960/2013: 314). For example, one might remark, "I understand your situation of an old and 'unfit' penal system and that penal reform would satisfy many demands you face." Gadamer did not structure his argument with the postcolonial context of our present discussion in mind, yet the effect of this context is to further reinforce the claim he is about to make. Why? Because dialogues between the Global

\footnotetext{
1 Some philosophers draw a distinction between I-Thou relations, that tend to be positive, and I-It relations, that are negative - that regard another not as a person but as an object — an "it." Gadamer, in fact, did not make this distinction and for that reason, the discussion in this article will follow Gadamer's formulation. For those wishing to explore this distinction in depth, see Buber (1970) and, rather tangentially but in the context of criminology, see Liebling (2015).

${ }^{2}$ Gadamer develops his arguments that apply to everyone using the gendered male form. Despite this being odious to the contemporary reader, I have retained it as written and do not append "[sic]" as a notation, which is distracting and, in its constant repetition, trite. Gadamer's writing is an historical text and I well recognize the gendered expression it contains.
} 
North and the Global South are almost always conditioned by the historicist presumption that Northern experience leads - that is, is temporally prior-to Southern "development" in a teleological story of progress through global historical time (Chakrabarty 2000). The "fiasco of the prison" is, after all, little more than a story of Northern experience. It is precisely this advanced experience that allows us to know that the other who calls for penal reform in the face of a crumbling system does not yet understand what he/she/they is/are wishing for and what he/she/they will bring upon himself/herself/themselves—which is, of course, the fiasco of the prison, imported, tropicalized.

Admonitions, such as "that international bodies, non-government organisations (NGOs), state officials and scholars must engage more honestly with the "truth about prisons"” (Drake 2018: 2) when dealing with the Global South, contain within them an important presumptive structure. It is that not only have we judged what is best (i.e., not more prisons) but that we also know what the other would decide were he/she/they to be fully informed of "the truth"-were he/she/they to know, in other words, what we know. In this way, we have, in a manner of speaking, "occupied" the other's mind. And here is the nub of Gadamer's argument. In this presumption, we claim "to understand the other better than the other understands himself" (1960/2013: 367). It is worthwhile at this point listening to Gadamer (1960/2013: 368) explain how this slides quickly into a relationship of domination:

By understanding the other, by claiming to know him, one robs his claims of their legitimacy. In particular, the dialectic of charitable or welfare work operates in this way, penetrating all relationships between men as a reflective form of the effort to dominate. The claim to understand the other person in advance functions to keep the other person's claim at a distance. We are familiar with this from the teacher-pupil relationship, an authoritative form of welfare work. In these reflective forms, the dialectic of the I-Thou relation becomes more clearly defined.

How should we respond? Must we cast aside our good intentions and knowledge of dangers that, with right reason, the other would recognize? Must we be allowed to step into the void our own experience anticipates? Is there anything to be done? The answer, for Gadamer and I think for us, too, as criminologists, is yes, but it requires dispensing with the self-regard that poisons the dialectic that we have just considered. The problem for ethical criminological practice that Gadamer's work poses is that well-meaning judgment-of, for example, what should or should not be exported to the South, or what caveats or health warnings really must be attached—often reduces to a form of mastery over another. To anticipate now conclusions that will be reached later in the article, I note that none of this aims to shut down communication-nothing in this requires that we should be silent or advocates a "do nothing" or "say nothing" approach. What it does do is invite us to reassess our normal modes - of how we communicate, how we learn and come to know-and, in so doing, to behave more reflexively. I will return to all this in a few moments. For now, though, and in the reflexive spirit that I am encouraging here, I want to pause my engagement with Gadamer to consider how his ideas might make sense across cultures. In particular, I want to check that they do not instantiate the very Global North-Global South knowledge domination I draw on them to repudiate. 


\section{Domination and the Ethics of Social Science Research: The Case of India's Dalits}

A particularly fruitful engagement with Gadamer's ideas can be found in India, which is, in fact, where I first came upon them. Scholarship there on research and ethics within a South Asian society, yet in contexts affected in myriad and complex ways by dominance and hierarchy, adds further critical insights for our discussion. I will focus first on the work of the Dalit anti-caste activist and political scientist, Gopal Guru (see 2002, 2005, 2011). In particular, I want to touch on a collection of essays he wrote with the philosopher of science, Sundar Sarukkai, as a conversation on the ethics of researching and theorizing Dalit experience and published as The Cracked Mirror: An Indian Debate on Experience and Theory (Guru and Sarukkai 2012). The term, "Dalit," itself, was popularized by Bhimraco Ramji Ambedkar (known as "Dr. Babasaheb Ambedkar"). Ambedkar wrote an influential essay, The Annihilation of Caste (1936/2016), played a key role in the drafting of the Constitution of India, and used this term, "Dalit," to name those human beings which the caste system in Hinduism considered sub-human and thus, literally, "untouchable." A significant part of independent India's history has been a story of welfare work and the tussle between reformers and caste conservatives over what power should be allowed to the country's "debased" and "backward" classes, of whom Dalits form a sizeable part (around 220 million in India today) (Census of India 2011; UN 2019).

To the many Indian observers, it seems clear that Dalit communities lack basic education and that, in the context of welfare work and political advancement, they do not possess the skills to diagnose - through research, writing, engagement-what their own community lacks or needs. Yet who can say what Dalits should know, or, in other words, what knowledge they should acquire? Who can declare what is best for Dalits as individuals or as a community? It is in this context that Guru connects with Gadamer. It is the perceived ability to see what others cannot see of their own experience or the possibilities before them that, at once, brings the welfare relationship into being and defines its hierarchical, dominating character. Reminding us that relationships of domination run not only North-South, Guru rejects arguments of India's Brahmanical, top of the "twice-born" castes that "they need to intervene in the Dalit situation" because their capacity to capture and represent the truth of the Dalit's position will advance Dalit lives (Guru and Sarukkai 2012: 25). Echoing Gadamer, Guru responds that doing so "involves a charity element which by definition is condescending," for it "constitutes a jajmani relationship, structurally involving a patron and a client" (Guru and Sarukkai 2012: 25). Let us think about this for a moment in the context of Northern claims to really know what Drake (2018: 12) refers to as "the "truth about prisons'." Here, the presumption is that if represented accurately-which is to say, if seen with the epistemic power of our critical Northern vision - the scales will fall from Southerners' eyes. The "undeniable truth" of the prison will be revealed. Southerners will, at last, see that its operation, and thus, very existence is, by definition, "exceptional, unconstitutional and continuing fiasco" (Drake 2018: 12).

The solution for Guru is that Dalits must come to knowledge and insight on their own terms, not through welfare work, "epistemological empowerment" or "epistemological charity" (Guru and Sarukkai 2012: 25) of Brahmanical patrons seeking to diagnose their needs or inform them of their better futures. Dalits should, Guru argues, "become the subject of their own thinking rather than becoming the object of somebody else's thinking" (Guru and Sarukkai 2012: 23). For not only is the well-meaning judgment of those who see or understand better than the Dalit himself or herself a usurpation, it also "creates 
legitimacy for the patron's existence in both the Dalit soul and Dalit society" (Guru and Sarukkai 2012: 26). Guru then elaborates on what he sees as the ethical violations inherent in the dialectic of welfare and charity work, but we need not dwell on them here.

We should, instead, turn to the response of his interlocutor, Sundar Sarukkai. In The Cracked Mirror: An Indian Debate on Experience and Theory (2012), Sarukkai observes that, at first blush, Guru appears to be invoking some kind of property title claim upon Dalit life and lived experience. It might seem, he says, that Guru, like many others in our contemporary times, is looking to "lived" experience as providing some moral right to arbitrate what can or cannot be said about his community—about Dalits—by outsiders. In our penal case study terms, it might be the equivalent of saying that only a Southern state knows what is good for its penal system and may declare as much. In an observation that provides further insight into the deeply ethical nature of Guru's argument, however, Sarukkai insists that such first blush observations are, in fact, wrong. Rather than making a claim to "copyright or patent" (Guru and Sarukkai 2012: 29), and rather than being "interested in whether the writing of the non-Dalits is complementary or derogatory about Dalits," Guru is, in fact, taking a position that is "ethical and normative": "non-Dalits have no moral right to theorize about Dalits" (Guru and Sarukkai 2012: 33; on "Dalit truth," see Roy 2020).

If we remove these arguments from their specifically Indian context, we see that they offer critical insights for our thinking about penal reform, penal exports, and Global North-Global South dialogues, more generally. It is that the ethical quality of our conduct - in this case, the flagging of dangers and the warnings made about prisons-is not determined, not conditioned, by the quality of what we have to say. That is, it matters not whether we have concluded "good" or "bad" things about the prison. To claim that theory formed on the anvil of Northern experience, and perhaps even reinforced by "tests" of "fit" in the odd far flung place, reveals a general truth that Southerners should apply to themselves and their world establishes a relationship of domination (Gadamer) or charity (Guru) simply by dint of its character. This leaves liberal progressivism facing something of a dilemma: robbed of the authority to engage and instruct on the basis of being rightof holding the truth-how might this knowledge travel? How might Global North-Global South dialogue develop? Does Guru's edict debar one person from offering any advice or insight to another? And how is one expected to behave as a moral actor if one cannot offer the important news of one's own experience, such as that prison does not work, when another is contemplating the matter of prisons? To answer that, we might return to Gadamer, but that return will be further strengthened by one additional detour into the thought of South Asian writers on experience and theory and the long shadow cast by the Global North.

\section{Northern Experience and the Artifice of Theory}

According to Banerjee and colleagues (2016: 46), the problem for Southerners thinking about themselves and their worlds "is not just that we think with concepts that carry the mark of histories not our own." It is equally and perhaps even more importantly "that these concepts do not wear the marks of their own historicity directly. Rather, they operate in the form of an erased historicity" (Banerjee et al. 2016: 46). Thus, what the Northern scholar approaches as an abstract concept or abstracted knowledge as theoretical proposition-such as the truth about prisons-typically is neither wholly abstracted nor entirely theoretical, if the distinction between theory and experience is to have any meaning. For 
those raised within Northern epistemic traditions, much of this is invisible. What Banerjee and her colleagues do (in fact, as just one movement within a much wider reappraisal of "the work of theory" (2016: 42)) is to draw to our attention the "unmediated slippage" that occurs between Northern experiences of the world and global constructs or concepts. "It is for this reason," they write, "that aspects of European history continue to function as philosophical/theoretical archetypes rather than as what it is, namely, empirical history" (Banerjee et al. 2016: 46). In an illustration of how this unique configuration of experience/theory works - and one, moreover, that has clear implications for our thinking about "the truth" of penal forms and their inevitable impacts - they point to a well-known set of events that unfolded in England during the eighteenth century. Here, they invite us to notice "[the] way that a specific chapter of English history, 'enclosure of the commons', comes to be endlessly retailed as 'primitive accumulation' - at once theoretical norm and historical necessity, undergirding the universal history of capital" (Banerjee et al. 2016: 46).

"Theoretical norm and historical necessity." I struggle to think of a more apt description of the way critical, well-meaning criminologists "retail" the truth of the prison and the futures that await all those who fall for its symbolic seductions. Northern empirical history reconfigured as universal history; experience as theory. And as Sarukkai reminds us, conclusions such as this do not rest on the content of what is so "retailed." We are not, here, in a debate about authenticity; we are speaking of "norm and form," to borrow from Paul Rabinow (1995). Like Guru, Banerjee and her colleagues also have a solution. It is more inclusive than Guru's, and it will bring us back around to where we left Gadamer.

Banerjee and colleagues (2016: 46) propose that, whereas epistemologies grounded in the European Enlightenment tradition erase historicity and, in so doing, "institute both exclusivity and universality at the same time," new theoretical insights-insights, that is, not circumscribed by the limits of Northern experience or the conceptual tools that abstract it only weakly - will be generated at points "where stakes are reconstituted and new possibilities opened." The mistake of the thought traditions most of us as criminologists work within is thus to imagine that our theoretical claims about phenomena that exist everywhere are strengthened by "test for fit" approaches that seek confirmation of Northern theoretical models (read, weakly abstracted Northern experience) in any conveniently to hand site in the Global South (take an African or South Asian postcolonial prison, for example). For Banerjee and colleagues, this is to misapprehend what theory and thought require in a global milieu. Thought or knowledge, they argue, "becomes 'theoretical' [only] when it liberates itself from its origins and opens itself out to strange places and times" (Banerjee et al. 2016: 50). Theory, in other words, is never actually theoretical until it transcends a singular context, such as societies of the North-meaning that whatever we think we know about the "truth of the prison," we must recognize it is neither normative nor signalling historical necessity but merely local, situated and inevitably insufficient. It is an ingredient that will contribute to new possibilities in a yet to be founded open dialogue. That would require a degree of humility not often apparent in progressive criminologies. These tend to be, as we have seen, surprising unreflexive in declamations about the truth of prisons or, indeed, many other features of our criminal justice landscapes. But the openness that humility requires is precisely what Gadamer was concerned with and so it is to him we should now return. 


\section{Towards a Norm of Ethical Engagement and an Epistemology of Dialogue}

Drawing together the work of South Asian scholars with Gadamer's diorama of human relations reinforces the scale of the ethical stakes at play and embeds such relations in a wider postcolonial epistemology. Such an epistemology requires new ways of thinking about the possibilities of knowledge and the foundations of truth. Here, we find a confluence in thinking among a variety of southernizing and postcolonial scholars. For Raewyn Connell (2007: 214), for example, classical social science must give way to "a new formation of knowledge"- a body of understanding that cannot be achieved simply "by heaping description on description." Instead, Connell (2007: 223) suggests, we must accept that "the only possible future for social science on a world scale involves a principle of unification" of knowledge. Dipesh Chakrabarty (2000) offers one method of doing so, the echoes of which we can now recognize. Aiming to "create plural normative horizons specific to our existence and relevant to the examination of our lives and their possibilities," Chakrabarty seeks to de-center or "provincialize" Europe. "The point of this," he argues, "is not to reject social science categories but to release into the space occupied by particular European histories sedimented in them other normative and theoretical thought enshrined in other existing life practices and archives" (Chakrabarty 2000: 20).

Yet, for all these scholars, the development of such an epistemology remains primarily a political project. For Banerjee and her colleagues (2016: 49), it can be understood as "a project of transforming the contemporary"-of "renewing and reconstituting thought"something, they argue, that "is not a neutral but a politically charged task." Such "contemporanising," as they refer to it, may be achieved only via methods that bring together disparate thought traditions, ways of experiencing life and of being in the world.

It is here that we may return to Gadamer, who will allow us to understand how such "a political act finer than any other of its kind" (Banerjee et al. 2016: 49) also represents the kind of deeply ethical attitude towards truth and practice demanded in Kant's deceptively simple formulation of his categorical imperative. The unifying, pluralizing and integrative practices these scholars propose is what Gadamer (1960/2013: 317) would refer to as a "fusion of horizons." Such horizons, for Gadamer, emerge out of the historicallyand, we may add, culturally - conditioned situation in which we each find ourselves. Both the point and the difficulty of situations, he observes, are the very fact of our being in them. Being unable to be outside them, we obviously struggle to have objective knowledge of them. We find ourselves positioned-having a certain standpoint that limits our view and thus the breadth of our vision. The horizon of which he speaks, then, is "the range of vision that includes everything that can be seen from a particular vantage point" (Gadamer: 1960/2013: 313). It is, of course, understandable that, taking in all we can see and comprehend from our vantage point in the Global North, we might believe ourselves to have found the truth-such as the truth about prisons. But for many looking south, the error, in this respect, is to have aligned with method at precisely the moment when an ethical demand is faced. For in looking across cultures, histories, ontologies and the sometimes "messy categories and meandering epistemologies" (White 2000: 5) with which those other than ourselves appear to make sense of their lives, our ascription to methodological objectivity works only to mask our situatedness. And it is this very situatedness that limits our capacity to apprehend and comprehend lives and worlds that are not ours-that are beyond our range of vision. Reflecting on the product of such "objectivity," Gadamer (1960/2013: 311) observes that "[i]n our understanding, which we imagine is so innocent because its results 
seem so self-evident, the other presents itself so much in terms of our own selves that there is no longer a question of self and other."

Thus, in our belief in having found the objective truth about prisons, the Global South loses its otherness to become but one more reflection of our own selves-of the Global North - albeit with a few things yet to learn. Our reason becomes right reason (truth seeing) — something available to the other who is imagined almost as a shadow of ourselves, delayed but ready to step forward into that place from where we stand and view the world. The self-evident truth of the prison-or whichever other progressive, well-meaning insight we bring forth to Southern people and places - thus misapprehends a moment demanding ethical connection and, instead, sees in it only an opportunity for instruction and truthtelling. The fundamental ethical challenge is thus to resist the desire-driven by method, natural in its seeming self-evidence-to subjugate another to our own horizons. The path to truth of any kind begins at the moment we open ourselves to the truth that another may impart - a truth that goes beyond the possibilities offered by our own vision, our own horizon. This marks a receptivity not only to the other but so, too, to the possibility that we, ourselves, might become somebody different by dint of this interaction.

This, says Gadamer, is what openness represents: it is to "experience the Thou truly as a Thou-i.e. not to overlook his claim but to let him really say something to us" (1960/2013: 369). To do otherwise is to decline what he terms "the mutuality of such a relation" and, in doing so, one "changes this relationship and destroys its moral bond" (1960/2013: 369). The dialogue that ensues thus has a profoundly ethical attitude because each is open to the truth claims of another that might arise within it. In this way, Gadamer (1960/2013: 317) explains, "understanding is always the fusion of these horizons supposedly existing by themselves" (emphasis in original) but ultimately combining to form a new shared horizon of understanding. As a matter of method, therefore, openness and dialogical engagement between "I and Thou" proceed not through providing answers-telling what is known, one's own truths - but, instead, consists in the art of questioning. Here, Gadamer speaks of the objects of our knowledge - think once again of the prison-being "broken open by the question": "The significance of questioning" in dialogue, Gadamer (1960/2013: 371) maintains, "consists in revealing the questionability of what is questioned." What, we might begin by asking, can be a prison?

Dialogue, therefore, appears in this formulation not as a metaphor for something else but as a method for reconciling the problem of different experiences, world views, and horizons of knowledge. Guy Widdershoven and Suzanne Metselaar (2012: 295) describe hermeneutics as "the theory of understanding through dialogue." The point, here, is not to become rigidly shackled to a hermeneutic method but to draw upon its guidance. Especially important in this respect is the ethical position of openness and its counterpart method of dialogic questioning. The primacy of the question within such dialogue flattens hierarchies. It shifts each participant's attention from telling what is known to contemplating what is not, as the horizons of another create a space for understanding that exceeds one's own world view.

Such a method - a dialogue established through practices of questioning, not tellingdoes not, in any way, undermine the Kantian primacy of human dignity, for it does not proscribe telling what one knows. It does not demand a withholding of the truths emerging from one's own situatedness. Rather, it embeds the process of their emergence in a discourse founded on reciprocity and engagement with the other's very difference and the differentness of the context or world within which our knowledge will need to find its relevance. With respect to penal reform, then, one would not begin with an answer-encapsulating "the truth about prisons"- but with a question that would allow the discourse 
on prisons or confinement more broadly to move, iteratively, somewhere new. Under the lights of what Banerjee and her colleagues (2016: 49) call "contemporanising," this would "involve critically engaging [other] thought, its concepts and categories, in a dialogue across times and places such that it produces new insights and new concepts that help us deal with new challenges of the present."

While the primacy of the question is constantly renewed by the openness of its possible answers - of what is not settled and what is thus indeterminate - the power of dialogue lies in the meeting of horizons. For as Gadamer observes, questions, themselves, are not infinitely open. They are, in fact, bounded by the horizon of the questioner and it is only through the dialogue, itself, that each party becomes aware of a space that combines old and new awareness and from which a next, entirely new, question might be drawn.

I have experienced this in my own work in several ways. I will mention one briefly by way of closing, lest this method be felt to be too arch or highly theoretical for the world of everyday criminology. In this case, my dialogic partners are Buddhist or scholars of Buddhism and questions about closed penal spaces are, in many ways, inseparable from the reverential position accorded closed monastic spaces in a society deeply steeped in Buddhist ways of thinking and being. These, of course, penetrate every form of life, thought and practice, and so to ask questions about the meaning of enclosure or confinement, its generative possibilities, how prison regimes or their alternatives might be shaped by faith and culture, and how offenders might best return to the milieu of community are but the first moves in a dialogue that takes in notions of aspirations, futures, reform and values. Thus, for example, one entry point to thinking about penal reform is better understanding the history and religious and cultural coding of forms of separation from society. While we have discussed here an institutional model—the prison-Himalayan Buddhism recognizes a deep history of banishment, retreat and labouring in practices of atonement for wrongs both social and spiritual. Milarepa, an eleventh-century Tibetan spiritual master, for example, atoned for his malicious use of shamanist powers through labour and, in so doing, restored his dharma. Until as recently as the 1970s, analogous forms of banishment or exile were practiced at the village level. Different interlocutors have reported different accounts of this. Unfortunately, as an element of customary justice, little formal trace of its village-level character and administration remains. Yet, at the same time, and even if only in a general way, a sense of what was once possible, that was once found at the intersection of faith, custom and penality, pervades reflections on the place of the prison there today. In such contexts, discourses on confinement are capable of operating on different levels. One revolves around the globalized prison model, along with suggestions for reform. Yet other discourses on punishment exist, too. They are less visible and, as an outsider, I became aware of their existence only gradually. They are not secret, but one does have to begin asking the right questions, by finding a grammar to open, or enter, a discourse shaped by horizons that are distinctly not my own. In doing so, I have begun to think far more expansively and creatively about what penal reform might entail and the places it might be possible to go. I know a lot about Northern prisons, but here, in these discussions, I forget about telling. Here, I am full of questions. My emerging conceptual or intellectual horizon for what might count as penal in this place, what resources might be brought to bear-often deep resources of cultural and religious meaning —offers a radically refigured vision of the possibilities of belonging, censure, and reintegration.

What resources lie in these traditions, powerful cultural codes, and grassroots memories of quite different penal forms? The end points of these discussions are not known, which is precisely where their power lies. But in imagining what is possible, I am drawn back to Banerjee and colleagues' observations on the syncretic dialogues of the Dalit reformer, Ambedkar, who 
straddled world views as disparate as modern constitutional legalism and ancient Buddhist tradition. Banerjee and colleagues (2016: 49) observe that in bringing:

Buddhist tradition to bear upon a deeply conflicted and unequal present, Ambedkar sought to make possible a future [for Dalits] that was impossible to realise only through reason of state or social mobilisation. It was a future that had to be philosophically accomplished first. Ambedkar sought to philosophically arrive at a future - a future that the present could not engender from out of its own logic-by staging a complex encounter between the modern and the non-modern and between tradition and countertradition in his thought.

It is, in this way, that we might hope to find in dialogues on things like the meanings of penal confinement or redemptive pathways to reintegration in a Buddhist context, the seeds of Ambedkar's "future that the present could not engender from its own logic."

\section{Conclusion}

What sort of ethical and methodological issues arise in southern criminology? What are the implications for knowledge production and for practice—for truth and method—as Northern or North-oriented criminologists look or to the Global South or, indeed, as criminologists of the Global South seek to negotiate long-standing structural inequalities and hierarchies of power within societies of the Global South? An adequate answer to these questions might occupy this nascent endeavor for some years to come. Here, I have attempted to lay a groundwork, to suggest how criminologists of both the Global North and the Global South might understand and anticipate the ethical demands that flow from interactions that traverse boundaries of power, knowledge, location, history, culture and the like. I have tried to step through these ethical challenges and their attendant methodological implications. Like Tariq Jazeel and Colin McFarlane (2010: 110, 121), who contemplated the "postcolonial politics of knowledge production," my aim has not been to offer up a "catch-all universal formula," but to stimulate more focussed discussion on the place and meaning of ethical conduct in criminology.

In pursuit of this, a first purpose of the article has been to illustrate my case via a fairly straightforward and non-exoticized, anodyne even, area of criminological work of interest to both the Global North and Global South. Here, I have used an example-the question of penal reform in countries of the Global South-that takes up a matter that within progressive criminological circles is regarded as uncontroversially a closed case: prisons are inherently and deeply problematic and efforts at reform typically further embed precisely that from which we wish to free ourselves. There is a small but important literature dating back to the 1980s on the export of such reforms to what was then known as the "Third World" and now the "Global South." For convenience, I have drawn on Drake's (2018) excellent summary of prisons' ills and the dangers of their export via reform programming under the guise of state building as a foil for thinking through a counter-case grounded in an ethics of dialogue. To jump ahead of myself a little, here, I should add that consistent with the work of South Asian writers on the ethics of research and theory in this article, I can make such a counter-argument without at all disputing the research on which Drake's argument rests. Thus, an important aim of this contemplation of ethics and method has been to find a way of looking at the kinds of human relationships encountered in southern criminological 
work that goes beyond ad-hoc judgments about what is "good" or "bad" and looks, instead, to such relationships in their broadest human context.

This is important to me on a personal level, as well as purely academic one, for I have been working through questions of penal reform with colleagues in different parts of the Global South for some time. It is that personal experience with Global North-Global South engagement that establishes a second purpose of this article, which is to think through an ethics of practice for criminologists. What is at stake when we venture to the Global South or when Southerners face each other across boundaries that might be equally as sharp? How might the ethical dimensions of our conduct exceed the boundaries of what is captured in the human research ethics forms and declarations favored by Northern universities? This article has attempted to work through such considerations but with a focus on something that frequently eludes the self-consciousness and reflexivity of progressive criminologists, which is the political and ethical implications of well-meaning judgment and the fine line that separates "doing good" from practices of domination. At its broadest political level, this can be understood within frameworks of imperialism, decolonization experiences, contemporary continuities with the past, and neocolonial or neo-imperial instincts and practices. Ethically, I have attempted to illustrate what is at stake by placing the work of the German hermeneuticist Hans-Georg Gadamer in conversation with that of South Asian scholars including Gopal Guru, Sundar Sarukkai, Prathama Banerjee, Aditya Nigam and Rakesh Pandey. For these latter writers, social science research and the uses and creation of knowledge are, inextricably and at once, ethical and political acts. Bringing them together with Gadamer, I suggest a formulation that I described above as norm of ethical engagement - that is, a set of prescriptions about what ethical engagement demandsand an epistemology of dialogue, describing the conditions under which knowledge may emerge and a method through which north and south may meet and speak as equals.

Acknowledgments This article emerged from a paper I delivered at the International Congress on Southern Criminology in Bogotá, Colombia, November 6-8, 2019. I thank the organizers of that conference and the editors of this special issue for their feedback and encouragement and the journal's anonymous reviewers for their engagement with the paper and its arguments. At the University of Sheffield, thanks go to Arushi Garg and Adam White for their inciteful comments and feedback on an early draft of the paper. I am thankful to Richard Whitecross at Edinburgh Napier University for a short lesson on some finer points of Buddhist history. I also thank my colleagues and interlocutors in South Asia who have given freely of their time and knowledge to engage me in dialogues that I hope have only just begun. As ever, errors or omissions are solely my own. Travel and fieldwork in South Asia were supported by a Global Challenges Research Fund grant administered by the University of Sheffield.

Open Access This article is licensed under a Creative Commons Attribution 4.0 International License, which permits use, sharing, adaptation, distribution and reproduction in any medium or format, as long as you give appropriate credit to the original author(s) and the source, provide a link to the Creative Commons licence, and indicate if changes were made. The images or other third party material in this article are included in the article's Creative Commons licence, unless indicated otherwise in a credit line to the material. If material is not included in the article's Creative Commons licence and your intended use is not permitted by statutory regulation or exceeds the permitted use, you will need to obtain permission directly from the copyright holder. To view a copy of this licence, visit http://creativecommons.org/licenses/by/4.0/.

\section{References}

Ambedkar, B.R. (1936/2016). The Annihilation of Caste: The Annotated Critical Edition. New Delhi: Navayana Press.

Banerjee, P., Nigam, A., \& Pandey, R. (2016). The work of theory: Thinking across traditions. Economic and Political Weekly, 51(37), 42-50. 
Blaustein, J. (2016). Exporting criminological innovation abroad: Discursive representation, "evidence-based crime prevention" and the post-neoliberal development agenda in Latin America. Theoretical Criminology, 20(2), 165-184.

Blaustein, J. (2017). Ethical criminologists fly economy: Process-related criminological engagement "abroad". In Armstrong, S., Blaustein, J., \& Henry, A. (Eds.), Reflexivity and Criminal Justice: Intersection of Policy, Practice and Research (pp. 357-379). London: Palgrave Macmillan.

Bosworth, M. (2017). Penal humanitarianism? Sovereign power in an era of mass migration. New Criminal Law Review, 20(1), 39-65.

Bowling, B. (2011). Transnational criminology and the globalization of harm production. In Bosworth, M., \& Hoyle C. (Eds.), What is Criminology? (pp. 361-379). Oxford: Oxford University Press.

Brisson-Boivin, K., \& O'Connor, D. (2013). The rule of law, security-development and penal aid: The case of detention in Haiti. Punishment and Society, 15(3), 515-533.

Buber, M. (1970). I and Thou / Martin Buber: A New Translation with a Prologue "I and You" and Notes by Walter Kaufmann. Trans. R.G. Smith. New York: Charles Scribner's Sons; Edinburgh: T\&T Clark.

Cain, M. (2000). Orientalism, occidentalism and the sociology of crime. The British Journal of Criminology, 40(2), 239-260.

Carrabine, E., Lee, M., \& South, N. (2020). Re-thinking public criminology: Politics, paradoxes, and challenges. In Henne, K., \& Shah, R. (Eds.), Routledge Handbook of Public Criminologies (pp. 21-33). Abingdon, Oxon, UK, and New York: Routledge.

Census of India. (2011). Census of India: Population Enumeration Data. Retrieved on August 27, 2021, from https://censusindia.gov.in/2011census/population_enumeration.html.

Chakrabarty, D. (2000). Provincializing Europe: Postcolonial Thought and Historical Difference. Princeton, NJ: Princeton University Press.

Clinard, M., \& Abbott, D. (1973). Crime in Developing Countries: A Comparative Perspective. New York: John Wiley.

Cohen, S. (1988). Against Criminology. New Brunswick, NJ: Transaction Publishers.

Connell, R. (2007). Southern Theory: The Global Dynamics of Knowledge in Social Science. Crows Nest, NSW: Allen and Unwin.

Cunneen, C. (2018). Indigenous challenges for southern criminology. In Carrington, K., Hogg, R., Scott, J., \& Sozzo, M. (Eds.), The Palgrave Handbook of Criminology and the Global South (pp. 19-41). Cham, CH:: Palgrave Macmillan.

Dikotter, F., \& Brown, I. (2007). (Eds.) Cultures of Confinement: A History of the Prison in Africa, Asia, and Latin America. Ithaca, NY: Cornell University Press.

Drake, D. (2018). Prisons and state building: Promoting "the fiasco of the prison" in a global context. International Journal for Crime, Justice and Social Democracy, 7(4), 1-15.

Ferrell, J. (2011). Disciplinarity and drift. In Bosworth, M., \& Hoyle, C. (Eds.), What is Criminology? (pp. 62-75). Oxford: Oxford University Press.

Fischer-Tine, H., \& Mann, M. (Eds.). (2004). Colonialism as Civilizing Mission: Cultural Ideology in British India. London: Anthem Press.

Gadamer, H-G. (1960/2013). Truth and Method. London: Bloomsbury.

George, L., Tauri, J., \& MacDonald, L. (2020). Indigenous Research Ethics: Claiming Research Sovereignty Beyond Deficit and the Colonial Legacy. Bingley, UK: Emerald Publishing.

Goyes, D. R. (2019). Southern Green Criminology: A Science to End Ecological Discrimination. Bingley, UK: Emerald Publishing.

Guru, G. (ed) (2005). Atrophy in Dalit Politics. Mumbai: Dalit Intellectual Collective.

Graham, W., \& Robertson, A. (2021). Exploring criminal justice policy transfer models and mobilities using a case study of violence reduction. Criminology and Criminal Justice. First Published: February 8, 2021. https://doi.org/10.1177/1748895821991607.

Guru, G. (2002). How egalitarian are the social sciences in India?, Economic and Political Weekly, 37(50), 5003-5009.

Guru, G. (2011). Humiliation: Claims and Context. New Delhi: Oxford University Press.

Guru, G., \& Sarukkai, S. (2012). The Cracked Mirror: An Indian Debate on Experience and Theory. New Delhi: Oxford University Press.

Harcourt, B. (2007). Against Prediction: Profiling, Policing and Punishing in an Actuarial Age. Chicago, IL: University of Chicago Press. https://doi.org/10.1177/14624745211025745.

Jazeel, T., \& McFarlane, C. (2010). The limits of responsibility: a postcolonial politics of academic knowledge production. Transactions of the Institute of British Geographers, 35(1), 109-124.

Johnstone, G. (2005). Research ethics in criminology. Research Ethics Review, 1(2), 60-66.

Jones, T., \& Newburn, T. (2007). Policy Transfer and Criminal Justice: Exploring US Influence Over British Crime Control Policy. Maidenhead, Berkshire, UK: Open University Press. 
Liebling, A. (2015). Description at the edge: I-It/I-Thou relations and action in prisons research. International Journal for Crime, Justice and Social Democracy, 4(1), 18-32.

Lohne, K. (2020). Penal humanitarianism beyond the nation state: An analysis of international criminal justice. Theoretical Criminology, 24(2), 145-62.

Rabinow, P. (1995). French Modern: Norms and Forms of the Social Environment. Chicago, IL: University of Chicago Press.

Reiman J. (1979). Research subjects, political subjects and human subjects. In Klockars, C., \& O’Connor, F. (Eds.). Deviance and Decency: The Ethics of Research with Human Subjects (pp. 33-57). London: Sage.

Roy, R. (2020). From postcolonial irony to Dalit truth: A perspective on experience. Economic and Political Weekly, 55(47), 47-53.

Stambøl, E. M. (2021). Neo-colonial penality? Travelling penal power and contingent sovereignty. Punishment and Society. First Published: June 22, 2021. https://doi.org/10.1177/14624745211025745.

Sumner, C. (ed.) (1982). Crime, Justice and Underdevelopment. London: Heinemann.

UN Department of Economic and Social Affairs, Population Division. (2018). World Urbanization Prospects: The 2018 Revision, Online Edition. Retrieved on August 20, 2021, from https://population.un.org/wup/ Download/.

UN Department of Economic and Social Affairs, Population Division. (2019). World Population Prospects 2019. Retrieved on August 20, 2021, from https://population.un.org/wpp/.

United Nations Office on Drugs and Crime (UNODC). (2020). Persons held unsentenced, counts and percentage of total persons held unsentenced. Retrieved on August 20, 2021, from https://dataunodc.un.org/data/ prison/total\%20persons\%20held\%20unsentenced

Walklate, S., \& Fitz-Gibbon, K. (2018). Criminology and the violence(s) of northern theorizing: A critical examination of policy transfer in relation to violence against women from the global north to the global south. In Carrington, K., Hogg, R., Scott, J., \& Sozzo, M. (Eds.), The Palgrave Handbook of Criminology and the Global South (pp. 847-865). Cham, CH: Palgrave Macmillan.

Walter, M. (2016). Indigenous peoples, research and ethics. In Adorjan, M., \& Ricciardelli, R. (Eds.), Engaging with Ethics in International Criminological Research (pp. 87-105). Abingdon, Oxon, UK, and New York: Routledge.

White, L. (2000). Speaking with vampires. Rumor and history in Colonial Africa. Berkeley, CA: University of California Press.

Widdershoven, G., \& Metselaar, S. (2012) Gadamer's Truth and Method and moral case deliberation in clinical ethics. In Kasten, M., Paul, H., \& Sneller, R. (Eds.), Hermeneutics and the Humanities: Dialogues with Han-Georg Gadamer (pp. 287-305). Leiden: Leiden University Press.

Publisher's Note Springer Nature remains neutral with regard to jurisdictional claims in published maps and institutional affiliations. 